\title{
Qual a contribuição da Agricultura Familiar na qualidade dos cardápios da alimentação escolar?
}

\author{
Ana Laura Benevenuto de Amorim¹, Semíramis Martins Álvares Domene ${ }^{2}$ e \\ Daniel Henrique Bandoni ${ }^{3}$
}

Objetivo: Avaliar a qualidade do cardápio do Programa Nacional de Alimentação Escolar de municípios do estado de São Paulo, segundo o percentual de aquisição de produtos da Agricultura Familiar. Método: Os municípios foram classificados, de acordo com o percentual de aquisição de gêneros alimentícios oriundos da Agricultura Familiar (AF). Trata-se de um estudo transversal, em que a partir de questionário com descrição do cardápio de uma semana, teve-se a avaliação pelo Indicador de Qualidade de Cardápios da Alimentação Escolar, frequência de ocorrência de grupos de alimentos e valor energético e de macro e micronutrientes. Todas as variáveis foram avaliadas segundo o percentual de aquisição da AF. Os dados foram expressos em mediana, valor mínimo e máximo e para verificar a diferença entre os grupos foi utilizado o teste Kruskal-Wallis e o Qui-Quadrado (para ambos foi considerada $p<0,05)$. Resultados: Foram avaliados os cardápios de 52 municípios. Encontrou-se diferença significativa apenas para carboidrato. Com relação aos grupos de alimentos, não foi identificada diferença estatiscamente significativa. Encontrou-se elevada presença de alimentos processados e ultraprocessados nos cardápios. Conclusão: Não foi possível identificar diferenças entre a frequência de oferta dos grupos de alimentos segundo o percentual de aquisição de $\mathrm{AF}$, assim como, quanto as características quantitativas da maioria dos nutrientes. No entanto, os dados mostram haver tendência a menor oferta de frutas nos municípios que estão comprando menos da AF. De modo geral, foram encontrados cardápios em desacordo com a base legal do PNAE.

Palavras-chave: Alimentação escolar; agricultura familiar; cardápio.

\section{What is the contribution of Family Farming to the quality of school meal menus?}

Objective: to evaluate the quality of the school feeding menus of municipalities in the state of São Paulo, according to the percentage of products acquired from the family farmers. Method: The municipalities were classified according to the percentage of acquisition of foods from Family Farming (FF). This is a cross-sectional study, in

${ }^{1}$ Pós-graduanda pelo Programa Interdisciplinar em Ciências da Saúde na Universidade Federal de São Paulo - UNIFESP - Campus Baixada Santista. Endereço para correspondência: Av. Dr. Epitácio Pessoa no 741, Ponta da Praia, Santos, SP. Cel.: +55(13)981022065. E-mail: analauraba@hotmail.com. http://orcid.org/0000-0003-0745-8201.

2 Docente do Curso de Nutrição - UNIFESP - Departamento de Políticas Públicas e Saúde Coletiva - Campus Baixada Santista. https://orcid.org/0000-0003-3003-2153.

${ }^{3}$ Docente do Curso de Nutrição - UNIFESP - Departamento de Saúde, Clínica e Instituições - Campus Baixada Santista. http://orcid.org/0000-0003-1638-1437. 
which, based on a questionnaire with a description of the week menu, the Quality Index for School Meal Menus was applied, frequency of occurrence of food groups, and energy and macro and micronutrient values. All variables were assessed according to the percentage of FF acquisition. The data were expressed as median, minimum and maximum values and to verify the difference between groups, the Kruskal-Wallis test and the Chi-Square test were used, both considered $p<0.05$. Results: The menus of 52 municipalities were evaluated. There was significant difference in the assessment of nutritional calculation for carbohydrate. Regarding food groups, no difference was found. A high presence of processed and ultra-processed foods was found on the menus. Conclusion: It was not possible to identify differences between the frequency of supply of the food groups according to the percentage of family farming acquisition, as well as to the quantitative characteristics of most nutrients. However, the data show a tendency towards a lower supply of fruits in the municipalities that are buying less from the family farming. In general, menus were found that did not comply with the PNAE legal basis.

Keywords: School feeding; family farm; agriculture; menu.

\section{INTRODUÇÃO}

O Programa Nacional de Alimentação Escolar (PNAE) é uma das mais importantes e abrangentes políticas de alimentação e nutrição do Brasil. Um das suas diretrizes é garantir a segurança alimentar e nutricional dos alunos da educação básica, de modo universal e contínuo ${ }^{[1]}$. Ao longo da sua trajetória o programa vivenciou avanços, sendo a descentralização de recursos financeiros uma delas (em 1994); a qual permitiu maior autonomia às Entidades Executoras na elaboração dos cardápios. A partir daí, aconteceu uma gradativa redução na oferta de alimentos formulados com o preparo de refeições realizadas nas escolas $[2,3]$, tornando o cardápio um elemento central para alcance dos objetivos do Programa.

O cardápio é definido como uma ferramenta que inicia o processo produtivo e serve como instrumento para o gerenciamento de uma unidade de alimentação e nutrição[4]. No âmbito do PNAE, o cardápio deve ser elaborado com a utilização de gêneros alimentícios básicos, que são considerados indispensáveis a uma alimentação saudável. Além disso, a Legislação determina oferta mínima de frutas e hortaliças, restrição da oferta de alimentos enlatados, embutidos, doces, alimentos compostos e preparações semiprontas; e proíbe fornecimento de bebidas com baixo teor de nutrientes. São estabelecidos também, parâmetros quantitativos de micro e macronutrientes, os quais devem ser supridos pela alimentação oferecida no ambiente escolar ${ }^{[1,5]}$.
Com a exigência da aquisição de gêneros alimentícios oriundos da agricultura familiar (AF) pela Lei no 11.947/2009, surgiu à possibilidade de aproximação entre a agricultura familiar e o resgate do patrimônio alimentar, reintegrando as dimensões da produção e do consumo de alimentos, no que o PNAE pode constituir um elo importante. A partir disso, espera-se que essa relação apoie-se em escolhas alimentares condizentes com o fortalecimento dessa atividade produtiva e com os princípios da alimentação saudável, de forma que a alimentação que o escolar tenha acesso esteja de acordo com essas premissas ${ }^{[0]}$.

Estudos têm mostrado que os alimentos mais presentes nas chamadas públicas da Agriculta Familiar para o PNAE são principalmente in natura com destaque aos orgânicos e agroecológico em algumas regiões do Brasil[7,8,9,10,11,12]. No entanto, poucos são os estudos que avaliaram os cardápios planejados após a implementação da Lei no 11.947/2009[13,14]. Para tanto, o objetivo do presente estudo foi avaliar a qualidade do cardápio de municípios do estado de São Paulo no ano de 2013, segundo o percentual de aquisição de produtos oriundos da AF.

\section{MÉTODOS}

Trata-se de um estudo transversal, que avaliou os cardápios elaborados para uma semana em escolas de ensino fundamental de municípios do Estado de São Paulo, referentes ao ano de 2013. Todos os municípios estavam elegíveis para participar do estudo. 


\section{Coleta de dados}

Foram realizadas tentativas de contato telefônico com os 645 municípios do Estado de São Paulo, obteve-se êxito em 611 casos. Nestes, os municípios foram inquiridos sobre a realização da aquisição de gêneros alimentícios oriundos da Agricultura/Empreendedorismo Familiar no ano de 2013; solicitou-se o nome completo do nutricionista e e-mail para posterior envio de questionário e carta de esclarecimento por meio eletrônico. O questionário foi efetivamente enviado via e-mail para 425 municípios, visto que nos demais ou não havia nutricionista ou o nutricionista estava recentemente no cargo e não dispunha das informações referentes ao período em estudo.

Para caracterizar a execução do PNAE nos municípios e verificar a aquisição de produtos da AF, solicitou-se de cada município, a seu critério, os seguintes dados de uma escola de ensino fundamental: nome da escola, número de alunos matriculados, refeições servidas, período, repetição de refeição e tipo de gestão e de cozinha, por meio de questionário estruturado.

Para avaliar as refeições oferecidas pelos municípios foi solicitada a descrição do cardápio de uma semana com valores per capita dos ingredientes das preparações. Quando a informação per capita não estava disponível, os municípios poderiam enviar a informação da quantidade total de alimentos utilizados no dia ou semana e o número de refeições oferecidas para posterior cálculo da quantidade per capita.

Se em 20 dias o nutricionista não encaminhasse o formulário respondido, o mesmo e-mail era encaminhado novamente; o procedimento de envio foi repetido cinco vezes. Dos 425 municípios que receberam o questionário, 55 municípios $(12,9 \%)$ responderam à pesquisa.

\section{Aquisição de alimentos da agricultura familiar}

Os municípios foram classificados em três grupos, de acordo com o percentual de aquisição de gêneros alimentícios oriundos da AF (auto declarado) para a alimentação escolar: municípios que não estavam comprando da agricultura familiar $(0 \%)$, que adquiriram até $29,99 \%$, e que adquiriram $30 \%$ ou mais.

\section{Características do município e da execução do PNAE}

Sabe-se que dependendo do tamanho do município, a realidade, a demanda e as prioridades são diferentes, tendo contribuição o Índice de Desenvolvimento Humano (IDH), economia local entre outros fatores. Os municípios foram agrupados segundo o número de habitantes, adaptando a classificação do IBGE[15] em: pequeno porte 1 (até 20.000 habitantes), pequeno porte 2 (de 20.001 a 50.000 habitantes), médio porte (de 50.001 a 100.000 habitantes) e grande porte (acima de 100.001 habitantes). Ressalta-se que tal adaptação foi necessária visto a classificação do IBGE ser ampla, não permitindo comparações entre os municípios participantes da pesquisa, visto que eles ficariam muito distribuídos.

Foram analisados: a presença ou ausência de cozinha na escola e/ou central; o período correspondente ao cardápio descrito no questionário referente à permanência do aluno na escola (parcial ou integral); o tipo de gestão do serviço (centralizada, terceirizada e/ou escolarizada); o número de alunos beneficiados pelo PNAE; o número de refeições servidas; e se havia oferta de repetição. O município informou se adquiriu produtos da AF no ano de 2013, e o percentual de compra ou valor em reais correspondente a esse último ano.

\section{Avaliação do cardápio}

Foram avaliadas todas as refeições presentes nos cardápios de uma semana para escolas de ensino fundamental. O cardápio encaminhado foi selecionado a critério do nutricionista.

Para avaliar os cardápios realizou-se duas análises qualitativas utilizando o Indicador de Qualidade para Cardápios da Alimentação Escolar (IQCAE) ${ }^{[16]}$ e a frequência de oferta de alimentos do grupo de frutas, hortaliças, pescados, processados e ultraprocessados ao longo da semana. A análise quantitativa foi realizada por meio do cálculo médio (na semana) de energia, macro e micronutrientes descritos na Legislação do PNAE[5]. 


\section{Indicador de Qualidade para Cardápios da Alimentação Escolar (IQCAE)}

O IQCAE é composto de 12 componentes, sendo seis grupos alimentares (cereais/tubérculos, leguminosas, vegetais, frutas, carnes/ovos, queijo/leite/iogurte) componentes do cardápio e indicadores complementares. Foram incluídos na análise todos os alimentos oferecidos de segunda a sexta-feira na semana analisada. O indicador, ainda, é sensível à adequação do tipo de cardápio, ao horário e oferta de outro alimento nos horários de entrada ou saída, recebendo pontuação adicional[16]. O Quadro 1 contém o modelo de aplicação do indicador.

Quadro 1. Componentes e pontuação do Indicador de Qualidade para Cardápios da Alimentação Escolar

\begin{tabular}{|c|c|c|c|c|c|c|c|}
\hline \multirow{2}{*}{\multicolumn{2}{|c|}{ Componente de aval. Diária }} & \multicolumn{6}{|c|}{ Valores das cédulas para respostas SIM } \\
\hline & & \multirow{2}{*}{$\begin{array}{c}\text { Segunda } \\
\text { feira } \\
0,10 \\
\end{array}$} & \multirow{2}{*}{$\begin{array}{c}\text { Terça feira } \\
0,10\end{array}$} & \multirow{2}{*}{$\begin{array}{c}\text { Quarta feira } \\
0,10 \\
\end{array}$} & \multirow{2}{*}{$\begin{array}{c}\text { Quinta feira } \\
0,10\end{array}$} & \multirow{2}{*}{$\begin{array}{c}\text { Sexta feira } \\
0,10\end{array}$} & \multirow{2}{*}{$\begin{array}{c}\text { Resultados } \\
0,50 \\
\end{array}$} \\
\hline 1 & Grupo cereais/tubérculos & & & & & & \\
\hline 2 & Grupo leguminosas & 0,10 & 0,10 & 0,10 & 0,10 & 0,10 & 0,50 \\
\hline 3 & Grupo vegetais & 0,20 & 0,20 & 0,20 & 0,20 & 0,20 & 1,00 \\
\hline 4 & Grupo frutas & 0,20 & 0,20 & 0,20 & 0,20 & 0,20 & 1,00 \\
\hline 5 & Grupo carne e ovos & 0,20 & 0,20 & 0,20 & 0,20 & 0,20 & 1,00 \\
\hline 6 & Grupo leite/queijo/iogurte & 0,20 & 0,20 & 0,20 & 0,20 & 0,20 & 1,00 \\
\hline 7 & $\begin{array}{l}\text { Horário do lanche ou } \\
\text { merenda compatível com a } \\
\text { refeição }\end{array}$ & 0,04 & 0,04 & 0,04 & 0,04 & 0,04 & 0,20 \\
\hline 8 & Uso de doce como refeição & $-0,20$ & $-0,20$ & $-0,20$ & $-0,20$ & $-0,20$ & $-1,00$ \\
\hline \multirow[t]{2}{*}{9} & Uso de embutidos & $-0,20$ & $-0,20$ & $-0,20$ & $-0,20$ & $-0,20$ & $-1,00$ \\
\hline & & 0,64 & 0,64 & 0,64 & 0,64 & 0,64 & 3,20 \\
\hline \multicolumn{2}{|c|}{ Componente de aval. Semanal } & \multicolumn{4}{|c|}{ Critério } & $\begin{array}{l}\text { Valor } \\
\text { atribuído }\end{array}$ & Resultados \\
\hline \multirow{3}{*}{10} & \multirow{3}{*}{$\begin{array}{l}\text { Uso de doce como } \\
\text { sobremesa }\end{array}$} & \multicolumn{4}{|c|}{$\begin{array}{l}\text { Se somatório das variáveis de Segunda a Sexta }=0 \text { ou } 1 \\
\text { (nenhum ou um dia com resposta SIM) }\end{array}$} & 0,00 & \multirow{3}{*}{$\begin{array}{c}\text { Somatória } \\
\text { dos itens de } \\
1 \text { a } 9+ \\
\text { item10 }\end{array}$} \\
\hline & & \multicolumn{4}{|c|}{$\begin{array}{l}\text { Se somatório das variáveis de Segunda a Sexta }=2 \text { ou } 3 \text { (dois } \\
\text { ou três dias com resposta SIM) }\end{array}$} & $-0,10$ & \\
\hline & & \multicolumn{4}{|c|}{$\begin{array}{l}\text { Se somatório das variáveis de Segundaa Sexta }=4 \text { ou } 5 \\
\text { (quatro ou cinco dias com resposta SIM) }\end{array}$} & $-0,20$ & \\
\hline \multirow{4}{*}{11} & \multirow{4}{*}{ Uso de formulados } & \multicolumn{4}{|c|}{$\begin{array}{l}\text { Se somatório das variáveis de Segunda a Sexta }=0 \text { (nenhum } \\
\text { dia com resposta SIM) }\end{array}$} & 0,00 & \multirow{4}{*}{$\begin{array}{c}\text { Somatória } \\
\text { dos itens de } \\
1 \text { a } 10+ \\
\text { item } 11\end{array}$} \\
\hline & & \multicolumn{4}{|c|}{$\begin{array}{l}\text { Se somatório das variáveis de Segunda a Sexta = } 1 \text { (um dia } \\
\text { com resposta SIM) }\end{array}$} & $-0,10$ & \\
\hline & & \multicolumn{4}{|c|}{$\begin{array}{l}\text { Se somatório das variáveis de Segunda a Sexta }=2 \text { ou } 3 \text { (dois } \\
\text { ou três dias com resposta SIM) }\end{array}$} & $-0,20$ & \\
\hline & & \multicolumn{4}{|c|}{$\begin{array}{l}\text { Se somatório das variáveis de Segunda a Sexta }=4 \text { ou } 5 \\
\text { (quatro ou cinco dias com resposta SIM) }\end{array}$} & $-0,40$ & \\
\hline \multirow[b]{2}{*}{12} & \multirow{2}{*}{$\begin{array}{l}\text { Outro alimento servido aos } \\
\text { alunos }\end{array}$} & \multicolumn{4}{|c|}{ Não } & 0,00 & \multirow{2}{*}{$\begin{array}{c}\text { Somatória } \\
\text { dos itens de } \\
1 \text { a } 11+ \\
\text { item } 12\end{array}$} \\
\hline & & \multicolumn{4}{|c|}{ Sim } & 0,20 & \\
\hline
\end{tabular}

Fonte: Belik W, Domene SMA, 2012[16],

A pontuação total gera um valor máximo de 5,4 por semana; ou seja, 1 ponto por dia para os grupos alimentares (no total de 5,0) e 0,4 pontos quando há compatibilidade entre horário de oferta e tipo de refeição e quando o município oferece outro alimento, além do cardápio regular da alimentação escolar. Os 
resultados da pontuação geraram um escore dos cardápios de cada município empregado para identificar as eventuais diferenças qualitativas. A oferta frequente de doces, formulados e embutidos pontua negativamente[8],

\section{Grupos de alimentos}

Foi verificada a frequência da oferta de alimentos dos grupos das frutas, hortaliças, pescados, processados e ultraprocessados. Optou-se por esses grupos baseando-se na Legislação do PNAE vigente e o Guia Alimentar, o qual utliza a classificação NOVA ${ }^{[17,18]}$.

Para frutas e hortaliças utilizou-se a frequência mínima de oferta de três vezes na semana, considerando a recomendação da Resolução no 26/2013[5].

O FNDE tem incentivado a inserção de pescados na alimentação escolar, visto que seu consumo é baixo. Sendo assim, e considerando a dificuldade de aquisição desse grupo de alimento em alguns municípios, estabeleceu-se a frequência mínima de 1 vez na semana a fim de verificar como tem sido a oferta desse alimento[19].

Utilizou-se a classificação NOVA[18] para os alimentos processados e ultraprocessados. Estudos apontam que alimentos desses grupos estão presentes na alimentação do brasileiro ${ }^{[20]}$, sendo assim, estabeleceu-se a frequência máxima de 1 vez na semana para os ultraprocessados e 3 vezes na semana para os processados, a fim de verificar a presença desses grupos na alimentação escolar.

\section{Cálculo nutricional}

Foi calculado o conteúdo diário de energia do cardápio e os nutrientes: carboidratos, proteínas e lipídeos de acordo com o percentual referente a contribuição energética; fibra em gramas; e vitamina C, cálcio, ferro, magnésio, zinco e sódio em microgramas. A partir desses valores nos cinco dias descritos no cardápio estabeleceu-se a média diária.

Para os cálculos nutricionais foram consultados, nessa ordem: Tabela Brasileira de Composição de Alimentos - TACO - (2011)[21], United States Department of Agriculture - USDA - (2011) ${ }^{[2]} \mathrm{e}$ rótulo dos alimentos processados e ultraprocessados relatados.

Ressalta-se que embora em 8 de maio de 2020 tenha ocorrido a revogação da Resolução 26/2013 com a publicação da Resolução 06 [23], no presente estudo fez-se referência apenas a Resolução 26, visto o momento da coleta dos dados (2013).

\section{ANÁLISE DOS DADOS}

Inicialmente, efetuou-se uma análise descritiva por meio de frequências absolutas e relativas, medida de tendência central (mediana) e de dispersão (mínimomáximo). Para avaliar a diferença entre as variáveis de estudo e os grupos de aquisição de produtos da AF, utilizou-se o teste não-paramétrico Kruskal-Wallis para as variáveis quantitativas e o Qui-Quadrado para as qualitativas, para ambos os testes considerou-se $p<0,05$. As análises foram realizadas no SPSS, versão 17.0.

\section{ASPECTOS ÉTICOS}

Todos os nutricionistas que participaram da pesquisa assinaram o Termo de Esclarecimento Livre e Esclarecido. O presente trabalho foi aprovado pelo Comitê de Ética e Pesquisa da Universidade Federal de São Paulo (UNIFESP) por meio do parecer no 464.931/2013.

\section{RESULTADOS}

Dos 55 municípios $(12,9 \%)$ que participaram da pesquisa, 13 encaminharam o questionário via correio e os demais por e-mail. Três municípios foram excluídos por falta de informações na descrição dos cardápios (lista incompleta de ingredientes que compunham a preparação e respectivas quantidades), portanto, totalizaram 52 municípios participantes da pesquisa. Desses, 14 (26,92\%) municípios referiram não comprar produtos oriundos da Agricultura Familiar em 2013, 15 municípios $(28,85 \%)$ adquiriram até $30 \%$ de produtos, e $23(44,23 \%)$ compraram $30 \%$ ou mais de alimentos da AF.

A Tabela 1 apresenta as características dos municípios e das escolas, além da classificação por percentual de aquisição de alimentos da Agricultura Familiar. A maioria dos municípios que participaram da pesquisa era de pequeno porte $1(n=23-44,24 \%)$. Esse mesmo grupo de municípios foi o que mais atingiu 
os $30 \%$ exigidos de compra de alimentos da $\mathrm{AF}(\mathrm{n}=11$ - 47,83\%). Apenas um município de grande porte referiu estar atingindo os $30 \%$ de aquisição da $\mathrm{AF}$.

Dos 52 municípios, $26(50,00 \%)$ oferecem uma refeição ao escolar durante sua permanência na escola, 24 (46,16\%) municípios servem duas refeições e $2(3,84 \%)$ cidades oferecem 3 ou mais, sendo esses os de período integral (essa informação não está apresentada na tabela).

Tabela 1. Características dos municípios e escolas descritas e percentual de aquisição de gêneros alimentícios provenientes da Agricultura Familiar. São Paulo, 2013

\begin{tabular}{|c|c|c|c|c|}
\hline \multirow{2}{*}{ Caracterização } & \multicolumn{4}{|c|}{ Compra da Agricultura Familiar - n (\%) } \\
\hline & $0 \%(\mathrm{n}=14)$ & $<30 \%(\mathrm{n}=15)$ & $\geq 30 \%(\mathrm{n}=23)$ & Total $(\mathrm{n}=52)$ \\
\hline \multicolumn{5}{|l|}{ Porte do município* } \\
\hline Pequeno 1 & $6(42,85)$ & $6(40,00)$ & $11(47,83)$ & $23(44,24)$ \\
\hline Pequeno 2 & $1(7,15)$ & $3(20,00)$ & $5(21,74)$ & $9(17,30)$ \\
\hline Médio & $1(7,15)$ & $2(13,33)$ & $6(26,08)$ & $9(17,30)$ \\
\hline Grande & $6(42,85)$ & $4(26,67)$ & $1(4,35)$ & $11(21,16)$ \\
\hline \multicolumn{5}{|l|}{ Cozinha na escola } \\
\hline $\operatorname{Sim}$ & $10(71,43)$ & $9(60,00)$ & $19(82,61)$ & $38(73,08)$ \\
\hline Não & $4(28,57)$ & $6(30,00)$ & $4(17,39)$ & $14(26,92)$ \\
\hline \multicolumn{5}{|l|}{ Tïpo de gestão } \\
\hline Centralizada & $11(78,57)$ & $14(93,33)$ & $18(78,26)$ & $43(82,09)$ \\
\hline Terceirizada & $3(21,43)$ & $1(6,67)$ & $5(21,74)$ & $9(17,31)$ \\
\hline \multicolumn{5}{|c|}{ Período de permanência do aluno na escola } \\
\hline Parcial & $14(100,00)$ & $14(93,33)$ & $22(95,65)$ & $50(96,15)$ \\
\hline Integral & $0(0,0)$ & $1(6,67)$ & $1(4,35)$ & $2(3,85)$ \\
\hline
\end{tabular}

A Tabela 2 apresenta a média, mediana, valores mínimos e máximos e desvio padrão obtidos a partir do IQCAE. Não foi encontrada diferença significativa, porém nota-se tendência à pior qualidade nos cardápios dos municípios que não compraram da $\mathrm{AF}$, havendo melhores pontuações no grupo intermediário $(<30 \%)$. Nenhum município recebeu a pontuação máxima de 5,4 .

Tabela 2. Pontuação dos cardápios obtida segundo o Indicador de Qualidade para Cardápios da Alimentação Escolar (IQCAE). São Paulo, 2013

\begin{tabular}{l|cccc}
\hline \multirow{2}{*}{ Pontuação cardápio } & \multicolumn{4}{|c}{ Compra da Agricultura Familiar } \\
\cline { 2 - 5 } & $0 \%(\mathrm{n}=14)$ & $<30 \%(\mathrm{n}=15)$ & $\geq 30 \%(\mathrm{n}=23)$ & Total $(\mathrm{n}=52)$ \\
\hline Média & 3,18 & 3,53 & 3,35 & 3,37 \\
Mediana & 3,02 & 3,60 & 3,60 & 3,59 \\
Mínimo & 2,20 & 2,30 & 1,40 & 1,40 \\
Máximo & 4,40 & 5,00 & 5,00 & 5,00 \\
Desvio padrão & 0,68 & 0,80 & 1,00 & 0,88 \\
\hline${ }^{*} p<0,05$ (Kruskal-Waallis) & &
\end{tabular}

É importante destacar que para o componente de avaliação referente ao horário em que a refeição era servida, se atribui pontuação máxima todas as vezes que se oferece uma refeição do tipo lanche até às 10:30h ou 
quando o cardápio consiste de uma refeição completa após esse horário. A mediana para todos os grupos, independente da aquisição da AF, foi de 0,00; assim, pode-se afirmar que tem sido ofertada a refeição completa até as 10:30h, ou seja, os escolares tem se alimentado de arroz, feijão, salada e prato proteico até esse horário e em alguns casos, há anteriormente a oferta de desjejum.

A oferta de doce como refeição foi encontrada em poucos municípios e a de doce como sobremesa não foi encontrada em nenhum. A oferta de outro alimento além da refeição regular ocorreu com maior frequência nos municípios que estão comprando da $\mathrm{AF}$, isso mostra que talvez o gestor que compra mais da $\mathrm{AF}$ tem o compromisso em oferecer um alimento suplementar, e ainda, talvez os alimentos da AF façam parte dessa alimentação complementar.

A Tabela 3 apresenta a frequência relativa e absoluta dos municípios a partir da ocorrência dos grupos frutas, hortaliças, pescados, processados e ultraprocessados, de acordo com o percentual de aquisição de gêneros da AF. Não foi encontrada significância para nenhum grupo. De modo geral, os municípios estudados não estão atingindo o recomendado no que diz respeito a oferta mínima de três porções de frutas e hortaliças. A oferta mínima de frutas esteve mais presente nos municípios que estavam atingindo os $30 \%$ ou mais da $\mathrm{AF}$. Ainda que não apresentado na tabela, nem definido na metodologia, em todos os cardápios encontrou-se presença diária de alimentos in natura ou minimamente processados.

Destaca-se a baixa presença de pescados $(\mathrm{n}=$ 9 - 17,31\%) e a elevada presença dos alimentos dos grupos de processados e ultraprocessados ( $\mathrm{n}=41-$ $78,85 \%, \mathrm{n}=46-88,46 \%$, respectivamente), independente do percentual de aquisição da AF. Um dado importante mostrou que alimentos processados estiveram presentes todos os dias da semana em 23 $(44,23 \%)$ municípios e os ultraprocessados em 29 $(55,77 \%)$, ou seja aproximadamente metade e mais da metade dos municípios oferecem diariamente alimentos processados e ultraprocessados, nessa ordem. Os ultraprocessados estiveram mais presentes nos municípios que estavam atingindo os 30\% de compra da $\mathrm{AF}$, porém acredita-se que isso não tenha uma relação positiva. Destaca-se que nove municípios não relataram produtos ultraprocessados em seu cardápio.

Os alimentos processados que mais apareceram foram: extrato de tomate, vinagre, milho em conserva, pão francês e ervilha em conserva, nesse ordem; entre os ultraprocessados, os mais frequentes foram: margarina, achocolatado, molho de tomate, biscoito, bebida láctea e salsicha, nessa ordem.

Tabela 3. Frequência dos municípios, a partir da frequência de ocorrência estabelecida para os grupos de alimentos, de acordo com o percentual de aquisição de gêneros da AF. São Paulo, 2013

\begin{tabular}{l|c|c|c|c|c}
\hline \multirow{2}{*}{$\begin{array}{c}\text { Grupo de } \\
\text { alimento }\end{array}$} & Frequência de & \multicolumn{4}{|c}{ Compra da Agricultura Familiar } \\
\cline { 3 - 6 } & ocorrência/semana & $0 \%(\mathrm{n}=14)$ & $<30 \%(\mathrm{n}=15)$ & $\geq 30 \%(\mathrm{n}=23)$ & Total $(\mathrm{n}=52)$ \\
\hline Hortaliças & $\geq 3$ & $12(85,71)$ & $14(93,33)$ & $19(82,61)$ & $45(86,54)$ \\
Frutas & $\geq 3$ & $6(42,86)$ & $6(40,00)$ & $15(65,22)$ & $27(51,92)$ \\
Pescados & $\geq 1$ & $3(21,43)$ & $1(6,67)$ & $5(21,74)$ & $9(17,31)$ \\
Processados & $\geq 3$ & $10(71,43)$ & $13(86,67)$ & $18(78,26)$ & $41(78,85)$ \\
Ultraprocessados & $\geq 1$ & $11(78,57)$ & $13(86,67)$ & $22(95,66)$ & $46(88,46)$ \\
\hline$* p<0,05$ (Qui-Quadrado)
\end{tabular}

A Tabela 4 apresenta valores nutricionais e energéticos, a partir da mediana e valores mínimo e máximo segundo o percentual de aquisição de grupos provenientes da AF. A diferença foi significativa para carboidratos, conforme aumentou o percentual de aquisição de gêneros alimentícios da AF.
A mediana da energia, vitamina $C$ e magnésio aumentaram conforme a maior aquisição de gêneros alimentícios da $\mathrm{AF}$, ainda que não tenham apresentado, estatisticamente, diferença.

Destaca-se que o cardápio de três municípios apresentaram valor calórico superior a 1000 calorias, 
sendo que apenas dois eram de período integral. Considerando que metade dos municípios (26 $50,00 \%$ oferecem uma única refeição durante a permanência na escola, o valor da mediana de sódio (no geral e nos grupos) foi alta.

Os valores dos nutrientes não foram comparados com a recomendação do PNAE, visto existirem recomendações diferentes por faixa etária para a modalidade de ensino fundamental, e ainda, pelo número de refeições ofertadas durante a permanência do escolar. Nenhum município encaminhou cardápio segundo as diferentes faixas etárias exigidas pela Legislação.

Tabela 4. Mediana e valores mínimo e máximo do percentual e quantidade de macronutrientes, quantidade de calorias e micronutrientes. São Paulo, 2013

\begin{tabular}{|c|c|c|c|c|c|c|c|c|c|c|c|c|}
\hline \multirow{3}{*}{ Nutriente/Energia } & \multicolumn{12}{|c|}{ Compra da Agricultura Familiar } \\
\hline & \multicolumn{3}{|c|}{$0 \%(\mathrm{n}=14)$} & \multicolumn{3}{|c|}{$<30 \%(\mathrm{n}=15)$} & \multicolumn{3}{|c|}{$\geq 30 \%(\mathrm{n}=23)$} & \multicolumn{3}{|c|}{ Total $(n=52)$} \\
\hline & Mediana & Mínimo & Máximo & Mediana & Mínimo & Máximo & Mediana & Mínimo & Máximo & Mediana & Mínimo & Máximo \\
\hline Carboidrato $(\%)^{*}$ & 56,96 & 52,54 & 67,77 & 62,71 & 55,61 & 73,73 & 63,42 & 35,12 & 70,53 & 62,85 & 35,12 & 73,73 \\
\hline Proteína $(\%)$ & 17,87 & 12,86 & 24,10 & 16,40 & 11,73 & 24,14 & 16,96 & 11,44 & 22,35 & 16,80 & 11,44 & 24,14 \\
\hline Lipídeo (\%) & 24,40 & 15,25 & 31,60 & 19,91 & 11,60 & 30,08 & 19,62 & 13,78 & 45,88 & 20,15 & 11,60 & 45,88 \\
\hline Energia (kcal) & 486,93 & 285,20 & 1069,14 & 550,33 & 243,73 & 1065,91 & 576,43 & 215,18 & 1061,63 & 545,31 & 215,18 & 1069,14 \\
\hline Fibra $(g)$ & 4,75 & 3,27 & 10,96 & 6,71 & 2,77 & 8,65 & 5,77 & 2,49 & 15,36 & 5,65 & 2,49 & 15,36 \\
\hline Vitamina C (mg) & 12,43 & 3,47 & 36,70 & 15,06 & 3,64 & 75,53 & 23,80 & 2,92 & 462,96 & 18,30 & 2,92 & 462,96 \\
\hline Cálcio (mg) & 70,54 & 26,60 & 318,10 & 70,15 & 26,39 & 283,63 & 117,49 & 20,08 & 310,87 & 92,52 & 20,08 & 318,10 \\
\hline Ferro (mg) & 2,59 & 1,82 & 6,45 & 2,89 & 1,22 & 5,17 & 2,75 & 1,18 & 5,87 & 2,76 & 1,18 & 6,45 \\
\hline Magnésio (mg) & 58,68 & 25,47 & 204,62 & 83,12 & 33,81 & 129,12 & 86,27 & 32,41 & 183,9 & 79,81 & 25,47 & 204,62 \\
\hline Zinco (mg) & 2,91 & 1,78 & 6,14 & 2,68 & 1,32 & 5,30 & 3,09 & 1,47 & 5,43 & 2,99 & 1,32 & 6,14 \\
\hline Sódio (mg) & 578,99 & 231,74 & 1645,81 & 692,87 & 383,95 & 1589,46 & 634,16 & 264,46 & 1720,83 & 679,54 & 231,74 & 1720,83 \\
\hline
\end{tabular}

\section{DISCUSSÃO}

O presente estudo não permite afirmar a contribuição da Agricultura Familiar na qualidade dos cardápios, ainda que os municípios que atingem os 30\% de compra da AF, tendem a ofertar mais a fruta. No entanto, é importante destacar que os achados da pesquisa evidenciam cardápios que precisam estar alinhados tanto as recomendações legais do PNAE, quando as do Ministérios da Saúde, afim de que assim possa contribuir com a promoção de uma alimentação saudável no ambiente escolar.

A maioria dos municípios participantes da pesquisa estava adquirindo alimentos da $\mathrm{AF}$, no entanto, apenas $44 \%$ compram o mínimo exigido pela Legislação. Os municípios de maior porte tiveram percentual de aquisição de alimentos menor, quando comparados com os municípios menores. Pesquisas de abrangência nacional e na região Sul do país [24], encontrou resultados semelhantes quanto à dificuldade de cidades maiores em adquirir gêneros da AF. Sousa et al. (2015) ${ }^{[25]}$ relataram que a logística exigida pelo PNAE para entrega nas escolas dos grandes centros exige esquemas complexos e de alto custo, sendo essa a especialidade dos grandes distribuidores e atacadistas que compõem o sistema alimentar convencional. Ressalta-se que, talvez, os municípios que compram da AF sentiram-se mais motivados em participar dessa pesquisa.

O Indicador de Qualidade dos Cardápios da Alimentação Escolar (IQCAE) é uma ferramenta de fácil aplicação para avaliação de cardápios, principalmente por não requerer a quantidade de alimentos oferecidos. Apesar de não ter sido encontrada diferença entre os municípios que compravam alimentos da $\mathrm{AF}$, a mediana do grupo que não estava comprando da $\mathrm{AF}$ apresentou pontuação inferior à dos demais grupos. Resultados semelhantes foram encontrados por outros atores que utilizaram a ferramenta e relacionaram com a compra da $A F^{[16]}$. Ainda que a literatura traga que os alimentos mais presentes nas chamadas públicas são frutas e hortaliças [7,8,9,10,11,12], não se pode afirmar que os municípios que compram da $\mathrm{AF}$ terão uma pontuação maior a partir desse indicador, visto ele ser formado por outros componentes. 
Na legislação do PNAE não há especificação se a refeição a ser ofertada ao escolar deve ser completa (tipo almoço) ou se pode ser um lanche, concomitantemente, não há estudos na literatura sobre isso. No entanto, estudos apontam que o horário que a refeição é oferecida pode influenciar diretamente no consumo da alimentação escolar ${ }^{26,27]}$.

Pesquisa encomendada pelo FNDE, em que se avaliou uma amostra de cardápios do Brasil no ano de 2011, encontrou que a maioria das escolas da região Sudeste não oferecia frutas e folhosos três vezes na semana $\left(64,5 \%\right.$ e $84,6 \%$, respectivamente) ${ }^{[28]}$. Em avaliação realizada em Santa Catarina ${ }^{22]}$ foi observado resultado semelhante. Estes resultados corroboram o presente estudo, demonstrando que a oferta de frutas e hortaliças não alcança o recomendado pela legislação do PNAE, de modo a não contribuir com uma alimentação saudável e adequada.

Ainda que incentivada a inserção do pescado na alimentação escolar, a oferta é baixa. Mesmo em municípios como Belém/PA e Florianópolis/SC que têm o pescado como hábito regional e valorizado na alimentação, não foi encontrada oferta superior a uma vez na semana ${ }^{[30]}$. Ainda, no Brasil, o pescado não é servido nenhum dia na semana em 93,8\% dos municípios, e na região Sudeste em 87,1\%[28].

A presença dos alimentos processados e ultraprocessados foi alta nos municípios analisados, resultado de elevada presença de alimentos ultraprocessados em municípios paulistas também foram encontrados por Alvarez e Villar (2019)[14]. Em estudo realizado em Santa Cataria encontrou-se elevada oferta de alimentos ricos em açúcar $(76,7 \%$ dos municípios ofertam três vezes na semana) e a oferta dos alimentos semi prontos ou prontos para consumo foi menor que uma vez na semana em 97,7\% dos municípios; ressalta-se que nesse estudo os derivados do leite não foram considerados ultraprocessados [29].

Os ultraprocessados estiveram mais presentes nos municípios que estavam atingindo os $30 \%$ de compra da $\mathrm{AF}$, porém não acredita-se que isso tenha uma relação positiva. Atrelado a isso, a compra da agricultura familiar foi mais presente em municípios menores; considerando que nesses municípios, muitas vezes há recursos menores para complementar o valor repassado pelo FNDE, a qualidade do cardápio poderá ser comprometida a depender da contrapartida que o município investirá.

Quanto à compra de alimentos processados produzidos por agricultores/empreendedores familiares, a dinâmica da comercialização desse tipo de produto com as escolas é considerada mais fácil quando comparada à dos alimentos in natura, que demandam estrutura como balanças, sacos plásticos e veículos com refrigeração, e ainda, tem menor tempo de prateleira; além do que, por ter valor agregado ao produto isso pode contribuir a atingir os $30 \%$ exigidos pelo Programa. Pesquisa que avaliou chamadas públicas paulistas verificou que $41,42 \%$ dos municípios analisados listaram alimentos processados, demonstrando assim, o interesse e disponibilidade do agricultor/empreendedor familiar em produzir esses gêneros alimentícios ${ }^{[0]}$.

O ambiente escolar deve ser promotor de uma alimentação saudável e adequada e atender à Legislação que restringe e pró́be alimentos desses grupos e não são compatíveis com a promoção de hábitos saudáveis 5 . Os ultraprocessados são caracterizados por seus ingredientes ricos em gorduras ou açúcares e, na maioria das vezes, além de apresentar alto teor de sódio e ser pobre em fibras ${ }^{[17]}$. Ressalta-se que a presença dos alimentos processados e ultraprocessados não é desejável, no entanto, isso vai depender da quantidade e periodicidade de oferta, se fará parte de uma preparação ou será a principal preparação da refeição.

A recomendação de sódio do PNAE, independente de modalidade de ensino e faixa etária, sendo de $400 \mathrm{mg}$ per capita quando ofertada uma refeição e $600 \mathrm{mg}$ per capita para duas refeições[5]. Considerando que $50 \%$ (26) dos municípios oferecem uma refeição, a quantidade de sódio está elevada ao observar as medianas, que foi superior a $600 \mathrm{mg} \mathrm{em}$ todos os grupos. Destaca-se que além desses alimentos fonte do micronutriente, notou-se, também, elevado per capita de sal variando entre menos de $1 \mathrm{~g}$ a $5 \mathrm{~g}$ em uma única refeição.

Não foi citada nos cardápios a presença de alimentos orgânicos e/ou agroecológicos, ainda que o Programa incentive sua aquisição ${ }^{[5,31]}$. A inserção de alimentos agrobiodiversos na alimentação escolar, como as diferentes variedades de cereais, leguminosas e legumes, os tubérculos e as hortaliças, é entendida como um dos aspectos promotores da sustentabilidade, 
relacionando-se com o resgate e a valorização cultural, bem como com o fortalecimento de sistemas alimentares de base agroecológica[25].

Ainda que a Legislação exija a elaboração de cardápios não só por modalidade de ensino mas por faixa etária, nenhum município enviou os cardápios seguindo essa exigência; este resultado também foi registrado em um estudo que avaliou cardápios do ensino fundamental da cidade de Belo Horizonte/MG[32].

Pesquisa realizada com amostra representativa das escolas municipais de um município mineiro avaliou os nutrientes disponíveis nos cardápios propostos e naqueles efetivamente oferecidos, em relação a energia, macronutrientes, fibras e para a maioria dos micronutrientes. Foram encontradas diferenças importantes entre os cardápios propostos e os consumidos, justificado por alterações nos cardápios e possivelmente, ausência de ficha técnica. Dos 210 cardápios analisados, identificou-se alteração, em relação ao planejado, em 166 (79\%), sobretudo em virtude da alegação de falta de ingredientes $(37,10 \%)$, porém destaca-se que $24,80 \%$ das alterações foram realizadas sem motivo[32].

Quanto ao cálculo nutricional, houve diferença para carboidratos, conforme aumentou o percentual de aquisição de gêneros alimentícios da AF; a compra de quantidades maiores de raízes e tubérculos da $\mathrm{AF}$ poderia ser uma razão para este resultado; no entanto, este dado não foi computado.

Considerando que 26 municípios (50\%) do presente estudo oferecem apenas uma refeição, ocorreu amplitude para o valor energético, abrangendo de pouco mais de 200 a mais de $1000 \mathrm{kcal}$. Contudo, como apontado por outros estudos ${ }^{[31]}$ o planejado dificilmente é executado, o que propicia uma lacuna e faz com que o trabalho de planejamento do cardápio realizado pelo nutricionista seja desconsiderado. O planejamento do cardápio desde a elaboração, a compra dos alimentos e principalmente execução são essenciais para boa execução do PNAE. O manipulador de alimentos deve conhecer o PNAE e não apenas as boas práticas de manipulação. É importante que esse ator conheça as diretrizes formais para a elaboração do cardápio, desde os alimentos a serem utilizados até a importância de atender ao planejamento elaborado pelo nutricionista.
Em alguns municípios, funcionários da escola consomem a alimentação escolar, sendo assim, não se sabe se quando $\mathrm{O}$ nutricionista respondeu $\mathrm{O}$ questionário informando o número de refeições servidas foram contabilizadas essas refeições. Em caso negativo, os valores apresentados podem estar superestimados. Ressalta-se que o recurso que o FNDE destina à alimentação escolar deve ser gasto, exclusivamente, com gêneros alimentícios ofertados aos escolares, e, portanto, as refeições ofertadas aos funcionários devem ser provenientes do recurso de contrapartida da Entidade Executora (EEx) $)^{[1]}$. Issa et al. (2014)[32] apontaram que a porção dos funcionários foi 1,5 maior que a do escolar em seu estudo.

Por fim, os achados nesse estudo concordam com o de Teo (2017) em que refere que a implementação da Lei no 11.947/2009 produziu um efeito positivo no perfil regional dos padrões de compras de alimentos do PNAE, no entanto a Lei não produziu alterações significativas nos padrões dietéticos, sendo necessário esforços coletivos pela natureza intersetorial do PNAE para promover saúde e desenvolvimento local[33].

A principal limitação do estudo foi o baixo número de municípios que participaram da pesquisa. Ainda que não desejável, o resultado de apenas 55 municípios terem participado, também é um indicativo da dificuldade em se obter informações precisas sobre os cardápios e as quantidades efetivamente oferecidas aos escolares. O motivo pode ser o nutricionista não ter o dado per capita, a falta de tempo para responder, entre outras justificativas.

\section{CONCLUSÃO}

Não foi possível identificar diferenças entre a frequência de oferta dos grupos de alimentos segundo o percentual de aquisição de $\mathrm{AF}$, assim como, quanto as características quantitativas da maioria dos nutrientes. No entanto, os dados mostram haver tendência a menor oferta de frutas nos municípios que estão comprando menos da AF.

Ainda que não tenha sido esse o objetivo da pesquisa vale destacar que a presença e frequência dos alimentos ultraprocessados foi alta, sendo necessárias normatizações mais rígidas com relação à oferta desses produtos na alimentação escolar. Atrelada à oferta desses produtos e elevada utilização de sal, a quantidade 
de sódio foi alta, de maneira geral. Concomitantemente, encontrou-se que a oferta de frutas e hortaliças não atende a recomendação da legislação. A avaliação de cardápios como forma de monitoramento da alimentação escolar deve ser efetivamente executada de forma a gerar indicadores de qualidade para a melhor gestão da política.

\section{REFERÊNCIAS}

[1] Brasil. Lei no 11.947, de 16 de junho de 2009. Dispõe sobre o atendimento da alimentação escolar e do Programa Dinheiro Direto na Escola. Diário Oficial da União. 200917 jun. p. 2.

[2] Peixinho AML. A trajetória do Programa Nacional de Alimentação Escolar no período de 2003-2010: relato do gestor nacional. Ciência e Saúde Coletiva [Internet]. 2013 [acesso em 2018 set 15];18(4):909-916. Disponível em: https://doi.org/10.1590/S1413-81232013000400002.

[3] Peixinho A, Balaban D, Rinkus L, Schwartzman F, Galante AP. Alimentação Escolar no Brasil e Estados Unidos. O Mundo da Saúde. 2011; 35(2):128-136.

[4] Abreu ES, Spinelli MGN, De Souza Pinto AM. Gestão de unidades de alimentação e nutrição. 7. ed. São Paulo: Editora Metha; 2019.

[5] Brasil. Fundo Nacional de Desenvolvimento da Educação, FNDE/MEC 2013. Resolução CD/FNDE no 26, de 17 de junho de 2013. Brasilia: FNDE/MEC; 2013.

[6] Teo CRPA, Monteiro CA. Marco legal do Programa Nacional de Alimentação Escolar: uma releitura para alinhar propósitos e práticas na aquisição de alimentos. Revista de Nutrição [Internet]. 2012 [acesso em 2017 out 10]; 25(5):657668. Disponível em: https://doi.org/10.1590/S141552732012000500010 .

[7] Toyoyoshi JY, Oliveira R, SantoS MSN, Galisa MS, Galante AP. Avaliação da aquisição de gêneros alimentícios provenientes da agricultura familiar para a alimentação escolar. O Mundo da Saúde. 2013; 37(3):329-335.

[8] Gonçalves HVB, Da Cunha DT, Stedefeldt E, De Rosso VV. Family farming products on menus in school feeding: a partnership for promoting healthy eating. Ciência Rural [Internet]. 2015 [acesso em 2017 out 15];45(12):2267-2273. Disponível em: https://doi.org/10.1590/0103$8478 \mathrm{cr} 20150214$.

[9] Amorim ALB, De Rosso VV, Bandoni DH. Acquisition of family farm foods for school meals: Analysis of public procurements within rural family farming published by the cities of São Paulo state Revista de Nutrição [Internet]. 2016 [acesso em 2018 jan 12];29(2):297-306. Disponível em: https://doi.org/10.1590/1678-98652016000200012.

[10] Triches RM, Barbosa LP, Silvestri F. Agricultura Familiar e Alimentação Escolar no Estado do Paraná: uma análise das chamadas públicas. Revista Paranaense de Desenvolvimento. 2016; 37(130):29-43.

[11] Ferigollo D, Kirsten VR, Heckler D, Figueiredo OAT, Perez-Cassarino J, Triches RM. Aquisição de produtos da agricultura familiar para alimentação escolar em municípios do Rio Grande do Sul. Revista de Saúde Pública [Internet]. 2017 [acesso em 2018 fev 2];51(6). Disponível em: https://doi.org/10.1590/s1518-8787.2017051006648.

[12] Teo CRPA, Baccarin G, Triches RM, Lutinski JA, Tagliett RL. Aquisição de alimentos da agricultura familiar para a alimentação escolar em Santa Catarina. Revista Grifos [Internet]. 2019 [acesso em 2020 abr 9];47. Disponível em: http://dx.doi.org/10.22295/grifos.v28i47.4653.

[13] Fuhr AL, Triches RM. Qualidade da alimentação escolar a partir da aquisição de produtos da agricultura familiar. Segurança Alimentar e Nutricional [Internet]. 2017 [acesso em 2018 mar 13];24(2):113-124. Disponível em: https://doi.org/10.20396/san.v24i2.8650514.

[14] Alvarez DB, Villar BS. Efeito da Lei do Programa Nacional de Alimentação Escolar na qualidade nutricional dos cardápios escolares. Segurança Alimentar e Nutricional [Internet]. 2019 [acesso em 2020 abr 4];26:1-13. e019030. Disponível http://dx.doi.org/10.20396/san.v26i0.8655583.

[15] Instituto Brasileiro de Geografia e Estatística - IBGE. Consulta Classes de tamanho da população dos municípios [Internet]. Rio de Janeiro; 2018 [acesso em 2018 abr 24]. Disponível https://ww2.ibge.gov.br/home/estatistica/populacao.

[16] Belik W, Domene SMA. Experiências de programas combinados de Alimentação Escolar e desenvolvimento local em São Paulo - Brasil. Agroalimentaria [Internet]. 2012 [acesso em 2016 nov 10];18(34):57-72. Disponível em: http://www.saber.ula.ve/bitstream/123456789/35379/1/a rt4.pdf.

[17] Brasil. Ministério da Saúde. Secretaria de Atenção à Saúde. Departamento de Atenção Básica. Guia alimentar para a população brasileira [Internet]. 2. ed. Brasilia: Ministério da Saúde; 2014 [acesso em 2016 nov 12]. Disponível em: https://bvsms.saude.gov.br/bvs/publicacoes/guia_aliment ar_populacao_brasileira_2ed.pdf. 
[18] Monteiro CA, Cannon G, Levy R et al. NOVA. The star shines bright. World Nutr [Internet]. 2016 [acesso em 2016 nov 10];7:28-38. Disponível em: https://worldnutritionjournal.org/index.php/wn/article/vi ew/5.

[19] Brasil. Fundo Nacional de Desenvolvimento da Educação FNDE/MEC. Nota Técnica no 004/2013 CGPAE/DIRAE/FNDE - Inclusão de pescado na alimentação escolar, de 11 de julho de 2013. Brasília: FNDE/MEC; 2013.

[20] Camargo RGM, Caivano S, Bandoni DH, Domene SMA. Healthy eating at school: consensus among experts. Rev. Nutr [Internet]. 2016 [acesso em 2020 jul 22];29:(6). Disponível em: https://doi.org/10.1590/167898652016000600006 .

[21] NEPA/UNICAMP. Tabela Brasileira de Composição de Alimentos. 4. ed. Campinas: NEPA/UNICAMP; 2011.

[22] United States Department of Agriculture. National Nutrient Database for Standard Reference [Internet]. 2004 [acesso em 2017 jan 12]. Disponível em: http://ndb.nal.usda.gov.

[23] Brasil. Fundo Nacional de Desenvolvimento da Educação, FNDE/MEC 2020. Resolução CD/FNDE no 06, de 08 de maio de 2020. Brasília: FNDE/MEC; 2020.

[24] Castellani ANA, Trentini T, Nishida W, Rossi CE, Costa LCF, Vasconcellos FAG. Purchase of family farm and organic foods by the Brazilian School Food Program in Santa Catarina state, Brazil. Revista de Nutrição [Internet]. 2017 [acesso em 2018 mar 15];30(5):651-662. Disponível em: https://doi.org/10.1590/1678-98652017000500010.

[25] Sousa AA, Silva APF, Azevedo E, Ramos MO. Cardápios e sustentabilidade: ensaio sobre as diretrizes do Programa Nacional de Alimentação Escolar. Revista de Nutrição [Internet]. 2015 [acesso em 2018 abr 11];28(2):217229. Disponível em: https://doi.org/10.1590/141552732015000200010 .

[26] Veiros MB, Martinelli SS. Avaliação qualitativa das preparações do cardápio escolar - AQPC Escola. Nutrição em Pauta. 2012;20(2):12.

[27] Locatelli NT, Canella DS, Bandoni DH. Fatores associados ao consumo da alimentação escolar por adolescentes no Brasil: resultados da PeNSE 2012. Cadernos de Saúde Pública [Internet]. 2017 [acesso em 2020 mar 30];33(4):e00183615. Disponível em: https://doi.org/10.1590/0102-311x00183615.
[28] Centro Colaborador em Alimentação e Nutrição Escolar da Universidade Federal do Rio Grande do Sul - CECANE UFRGS. Resumo executivo - Composição nutricional da alimentação escolar no Brasil: uma análise a partir de uma amostra de cardápios. Porto Alegre: CECANE UFRGS; 2011.

[29] Vidal GM, Veiros MB, Sousa AA. School menus in Santa Catarina: Evaluation with respect to the National School Food Program regulations. Revista de Nutrição [Internet]. 2015 [acesso em 2019 nov 07];28(3):277-287. Disponível em: https://doi.org/10.1590/1415-52732015000300005.

[30] Gabriel CG, Costa LCF, Calvo MCM, Vasconcelos FAG. Planejamento de cardápios para escolas públicas municipais: reflexão e ilustração desse processo em duas capitais brasileiras. Revista de Nutrição [Internet]. 2012 [acesso em 2019 abr 20]:25(3):363-372. Disponível em: https://doi.org/10.1590/S1415-52732012000300006.

[31] Brasil. Fundo Nacional de Desenvolvimento da Educação, FNDE/MEC 2015. Resolução CD/FNDE no 04, de 02 de abril de 2015. Brasília: FNDE/MEC; 2015.

[32] Issa RC, Moraes LF, Francisco RRJ, Santos LC, Anjos AFV, Pereira SCL. Alimentação escolar: planejamento, produção, distribuição e adequação. Revista Panamericana Salud Publica [Internet]. 2014 [acesso em 2019 abr 12];35(2):96-103. Disponível em: https://www.scielosp.org/article/rpsp/2014.v35n2/96-103.

[33] Teo CRPA. The partnership between the Brazilian School Feeding Program and family farming: a way for reducing ultra-processed foods in school meals. Public Health Nutricion [Internet]. 2018 [acesso em 2020 abr 09];21(1):230$237 . \quad$ Disponível em: https://doi.org/10.1017/S1368980017002117. 